\title{
The Open Dentistry Journal
}

\section{RESEARCH ARTICLE}

\section{The Effect of Scaling and Root Planning on Salivary TNF- $\alpha$ and IL-1 $\alpha$ Concentrations in Patients with Chronic Periodontitis}

\author{
Masoome Eivazi ${ }^{1}$, Negar Falahi ${ }^{2}$, Nastaran Eivazi ${ }^{3}$, Mohammad Ali Eivazi ${ }^{4}$, Asad Vaisi Raygani ${ }^{5}$ \\ and Fatemeh Rezaei, ${ }^{6, *}$ \\ ${ }^{I}$ Department of Periodontics, School of Dentistry, Kermanshah University of Medical Sciences, Kermanshah, Iran \\ ${ }^{2}$ School of Dentistry, Kermanshah University of Medical Sciences, Kermanshah, Iran \\ ${ }^{3}$ Department of ENT, School of Medicine, Kermanshah University of Medical Sciences, Kermanshah, Iran \\ ${ }^{4}$ Department of Pharmacoeconomics and Pharmaceutical Management, School of Pharmacy, Shahid Beheshti \\ University of Medical Sciences, Tehran, Iran \\ ${ }^{5}$ Department of Biochemistry, School of Medicine, Kermanshah University of Medical Sciences, Kermanshah, Iran \\ ${ }^{6}$ Department of Oral Medicine, School of Dentistry, Kermanshah University of Medical Sciences, Kermanshah, Iran
}

Received: May 07, 2017

Revised: August 24, 2017

Accepted: October 11, 2017

\section{Abstract:}

\section{Objective:}

Periodontitis is one of the main diseases in the oral cavity that causes tooth loss. The host immune response and inflammatory factors have important role in periodontal tissue. The current study was done with the objective to determine the effect of scaling and root planning on the salivary concentrations of tumor necrosis factor-alpha (TNF- $\alpha$ ) and interleukin-1-alpha (IL-1 $\alpha$ ).

\section{Methods:}

In this quasi-experimental clinical trial, 29 patients with chronic periodontitis and 29 healthy subjects without periodontitis were studied. Clinical examination findings and salivary TNF- $\alpha$ and IL-1 $\alpha$ (using ELISA method) were compared before and after scaling, root planning.

\section{Results:}

Before starting treatment, salivary TNF- $\alpha$ and IL-1 $\alpha$ concentrations were higher in healthy control group than in periodontitis group $(P<0.05)$. Non-surgical treatment increased the concentration of these two biomarkers in the saliva. However, increase in IL-1 $\alpha$ concentration was not statistically significant $(P=0.056)$. There was a negative relationship between TNF- $\alpha$ and IL-1 $\alpha$ levels with pocket depth and attachment loss $(P<0.05)$.

\section{Conclusion:}

Scaling and root planning improved periodontal disease indices and salivary TNF- $\alpha$ and IL-1 $\alpha$ levels.

Keywords: Chronic periodontitis, Non-surgical treatment, Saliva, TNF- $\alpha$, IL-1 $\alpha$, ELISA method.

\section{INTRODUCTION}

Periodontitis is one of the leading causes of tooth loss which usually occurs in those older than 40 years [1] . Microbial agents, environmental factors, and genetic causes play role in the development and progression of

\footnotetext{
* Address correspondence to this author at the Department of Oral Medicine, School of Dentistry, Kermanshah University of Medical Sciences, Kermanshah, Iran; Tel: 98-918-8371081; E-mail: f.rezaei@kums.ac.ir
} 
periodontitis [2]. Evidence shows that the prevalence of periodontitis varies globally. In Asian countries, this condition has been reported to be more prevalent and more severe [3]. Periodontitis affects about $50 \%$ of adult population in the US who age more than 30 years. The prevalence of periodontitis increases with aging [4]. Periodontitis is more common in males and also it is more severe in cigarette smokers $[5,6]$. Periodontitis is not just a common oral disease. It reflects persistent immune system activation and is associated with conditions such as vascular diseases, and increased risk of cardiovascular diseases, diabetes, rheumatoid arthritis, and premature delivery [7 - 11]. Periodontitis risk factors include pathogens, lifestyle, psycho-social factors, chronic diseases, and genetic factors [12]. It is now widely accepted that main pathogenesis behind periodontitis is a polymicrobial process [13]. Gingival epithelial cells secrete inflammatory cytokines such as tumor necrosis factor-alpha (TNF- $\alpha$ ), interleukin-1-alpha (IL-1 $\alpha$ ), IL-1 $\beta$, TNF$\beta$, IL-8, and IL-6 in response to pathogens [14].

Even though immune system activity to oppose pathogen factors is necessary, irregular immune system activation can result in chronic inflammation and consequently cause gradual destruction of periodontal tissues [15]. Imbalanced immune system response can be elicited due to genetic and epidemiologic factors such as gender, age, cigarette smoking, and systemic diseases $[16,17]$. Cytokines are polypeptides that are produced in response to microbes and other antigens and modulate immune and inflammatory reactions. The effect of cytokines can be local or systemic. A cytokine can affect production and action of other cytokines [18]. IL-1 family has major role in initiation and continuation of immune and inflammatory responses [19 - 21]. IL-1 is a polypeptide with a wide range of actions such as modifying other inflammatory mediators including cytokines and prostaglandin E2, adhesion molecule expression regulation in endothelial cells, induction of osteoclast formation and stimulation inside bone marrow, induction of metalloproteinase release from macrophages and other cells [22]. IL-1 has two active forms: IL-1 $\alpha$ and IL-1 $\beta$. In addition to monocytes, other cells like macrophages, T lymphocytes, fibroblasts, vascular, skin, and brain cells can produce Il-1. IL-1 $\alpha$ is also called pro-inflammatory factor as this activates genes related to immune and inflammatory systems.

TNF- $\alpha$ as a pro-inflammatory cytokine and immune system modulator has a major role in pathogenesis of various inflammatory conditions inside the human body [23, 24]. This inflammatory marker has some other minor activities such as inflammatory cells recruitment, bone resorption via IL-1, stimulation of granulocyte macrophage colony stimulating factor, collagen production inhibition, collagenase induction inside tissues, and induction of osteoclast differentiation via granulocyte macrophage colony stimulating factor [25 - 28]. Similarities between IL-1 and TNF effects are amazing as these two cytokines and their receptors are different structurally. TNF- $\alpha$ causes, directly or indirectly, bone resorption and its formation inhibition [29].

Non-surgical therapy including scaling and root planning is effective treatment for periodontal diseases [30]. Low intensity ultrasonic waves activate cellular growth signaling pathway and stimulate circulating angiogenic cells [31, 32].

Saliva is a complex fluid, produced by major and minor salivary glands. It contains composition such as has inflammatory mediators that play important role in oral health. Saliva composition, naturally or under certain conditions, varies in different individuals $[33,34]$. The relationship between some inflammatory mediators in saliva and periodontitis pathogenesis has been established in some studies. The question rises here is that whether these biomarkers (TNF- $\alpha$ and IL-1 $\alpha$ ) can have relationship with success rate of non-surgical treatment for chronic periodontitis.

\section{MATERIALS AND METHODS}

A total of 58 subjects who presented to the Clinic of Dentistry School in Kermanshah (Iran) in 2015-16 were recruited for this quasi-experimental clinical trial. 29 subjects had chronic periodontitis based on definitions made by the American Academy of Periodontology and 29 subjects did not have periodontitis and gingivitis as a control group. All subjects were examined by a dentist (researcher). Inclusion criteria consisted of having at least 20 teeth, minimum age of 18 years and without any systemic diseases that can affect the periodontium. Inclusion criteria for periodontitis group also required presence of attachment loss and bone destruction in more than $30 \%$ of dental areas for at least 3 months [35]. Those who had received antibiotics in the last 2 months, long-term treatment by non-steroidal anti inflammatory drugs (NSAIDs), smokers, alcohol drinkers, periodontal treatments in the last 6 months, mucosal inflammatory conditions such as lichen planus or recurrent aphtus stomatitis, and pregnant or breastfeeding women were excluded.

The study protocol was approved by the Ethics Committee of Kermanshah University of Medical sciences, 
Kermanshah, Iran (KUMS REC 1395.128). The study protocol was registered at the Iranian Registry of Clinical Trials (IRCT2016052825649N3).

Firstly, the patients were examined and if inclusion criteria were met, they were informed orally about the study objectives. If agreed to participate, written informed consent was obtained from the patient. Periodontal indices such as pocket depth, attachment loss, bleeding on probing, and the plaque index were documented by a dentist before and 30 days after scaling. The pocket depth (the distance between gingival sulcus base and its margin) was measured in four locations using the Williams probe. Attachment loss, which is the distance between cementoenamel junction and gingival sulcus base, was determined by standard technique. The O'Leary plaque index was also documented.

Before non-surgical therapy, $5 \mathrm{~mL}$ of non-stimulated saliva was collected in sterile tubes using the method that Navazesh described in 2014 [36]. Saliva was collected when the patient was seated and head was slightly tilted forward with eyes open. It should be mentioned that the subjects were instructed not to chew gums, brush teeth, eating and drinking for one hour prior to collecting saliva samples. Also, participants washed their mouth for 2 minutes with normal saline prior to collecting saliva samples. The samples were stored at ice packages before transfer to the laboratory which was done up to 2 hours after getting the samples. The samples were centrifuged for 20 minutes at 2000-3000 rpm and after transfer to microtubes with cap were kept at - $20^{\circ} \mathrm{C}$ till ELISA test was done.

After collecting the primary sample, the patients underwent scaling and root planning and hygiene education. The scaling and root planning were done by ultrasonic device (WOODPECKER ${ }^{\circledR}$ made in china) by a dentist. The second salivary sample was collected one month after scaling by the same method described above. The periodontal indices were assessed once more. As a period of 1-2 weeks is usually required to allow the injuries occurred during scaling to be healed and epithelialized [37], periodontal examination and collection of salivary samples were done after 30 days to ensure periodontal condition has improved. Salivary TNF- $\alpha$ and IL- $1 \alpha$ levels were measured by ELISA method using diagnostic kits manufactured by Hangzhou EASTBIOPHARM Co., Ltd. For measurement of the concentrations, ELISA kits for serum, blood, and saliva samples with sensitivity $1.25 \mathrm{ng} / \mathrm{L}$ for TNF- $\alpha$ and $0.54 \mathrm{pg} / \mathrm{mL}$ for IL- $1 \alpha$ were used.

The subjects of the control group were selected considering they were compatible with regard to age and gender with the periodontitis group. The control group did not have periodontitis or any of the exclusion criteria. After getting written informed consent, non-stimulation salivary samples were collected in the control group with the same instructions described previously.

The analyses were done by the SPSS software for Windows (ver. 16.0). In order to determine the normal distribution of the data, the Shapiro-Wilk test was used. If the data had normal distribution, the independent sample t-test was used to compare the data between periodontitis and control groups. If the data did not have a normal distribution, the Mann-Whitney $U$ test was used for this purpose. In order to compare the data before and after non-surgical therapy, the Wilcoxon test was applied. In order to determine the relationship between the variables, the Spearman's correlation test was used. The significance level was set at 0.05 .

\section{RESULTS}

There were 13 males and 16 females in each group. Mean $( \pm \mathrm{SD})$ ages of periodontitis and control groups were respectively $38.59( \pm 12.46)$ and $31.28( \pm 8.49)$ years. Comparison of periodontal clinical parameters in periodontitis group showed improvement after non-surgical treatment. Periodontal pocket depths before and after treatment were 2.4 (0.56) and 1.7 (1.65 to 2.11), respectively. Mean clinical attachment loss before treatment was $2.4(0.92)$ which reached to 2.3 (1.7 to 2.7$)$ after the treatment. Bleeding on probing was $2.9(0.92)$ before therapy and reached to $15(5.3$ to 25$)$ after treatment. Periodontal clinical index showed significant improvement after treatment $(P<0.001)$; (Table 1).

Table 1. Clinical parameters of periodontitis group before and after the therapy.

\begin{tabular}{|c|c|c|c|}
\hline Variable & BT & AT & P value \\
\hline PD $(\mathrm{mm})$ & $2.39( \pm 0.56)$ & $1.71(1.65$ to 2.11$)$ & $<0.001$ \\
\hline CAL $(\mathrm{mm})$ & $2.93( \pm 0.92)$ & $2.3(1.7$ to 2.7$)$ & $<0.001$ \\
\hline BOP $(\%)$ & $45.5( \pm 20.8)$ & $15(5.3$ to 25$)$ & $<0.001$ \\
\hline PI $(\%)$ & $85(72$ to 95$)$ & $53.7( \pm 23.5)$ & $<0.001$ \\
\hline
\end{tabular}

Abbreviations: $\mathrm{BT}=$ before treatment; $\mathrm{AT}=$ after treatment, $\mathrm{PD}=$ pocket depths, $\mathrm{CAL}=$ clinical attachment loss, $\mathrm{BOP}=$ bleeding on probing, $\mathrm{PD}=$ periodontal index

Wilcoxon test 
Mean (SD) salivary TNF- $\alpha$ levels in periodontitis before and after the therapy and control group were 51.0 (17.7), 58.0 (15.33) and 72.4 (28.4) respectively. Comparison of mean TNF- $\alpha$ level between periodontitis and control groups before and after the treatment showed significant differences $(P<0.05)$. Salivary TNF- $\alpha$ concentration increased after the treatment, the change was statistically significant $(P=0-02)$ (Table 2).

Table 2. Comparison between salivary TNF- $\alpha$ and IL-1 $\alpha$ before and after treatment and control group.

\begin{tabular}{|c|c|c|c|c|c|c|}
\hline $\boldsymbol{P}$-Value3 & $\boldsymbol{P}$-Value2 & Control Group & $\boldsymbol{P}$-Value1 & After Treatment & Before Treatment & \\
\hline $0.042^{* *}$ & $0.002 *$ & $72.4 \pm 28.4$ & $0.021^{*}$ & $58.02 \pm 15.33$ & $51.06 \pm 17.77$ \\
\hline $0.07^{* *}$ & $0.002 *$ & $97.54 \pm 66.04$ & $0.056^{*}$ & $65.67 \pm 38.31$ & $54.66 \pm 31.50$ \\
\hline
\end{tabular}

$P$-Value $1=$ comparison between before and after treatment. $P$-Value $2=$ comparison between before treatment and control group. $P$-Value $3=$ comparison between after treatment and control group $* \mathrm{u}$ man whitney test $* *$ t-test

Mean (SD) salivary IL-1 $\alpha$ levels in periodontitis groups before and after the treatment and control group were 54.7 (31.5), 65.7 (38.31) and 97.5(66.04). Comparison of mean TNF- $\alpha$ level between periodontitis and control groups before and after the treatment showed significant differences $(P<0.05)$; Although, salivary IL-1 $\alpha$ concentration increased after the treatment, the change was not statistically significant $(p=0.056)$ (Table 2 ).

There was a negative relationship between TNF- $\alpha$ and IL-1 $\alpha$ levels with pocket depth and attachment loss (Table 3).

Table 3. Correlation coefficient between PD and CAL with TNF- $\alpha$ and IL-1 $\alpha$ levels.

\begin{tabular}{|c|c|l|l|}
\hline CAL & PD & $R$-value & $p$-value \\
\hline-0.311 & $-0 / 294$ & $R$-value \\
0.017 & 0.025 & $p$-value & IL-1 $\alpha$ \\
\hline-0.312 & -0.299 & 0.023 & \\
0.017 & $0 . \alpha$ & \\
\hline
\end{tabular}

$\mathrm{PD}=$ pocket depths, $\mathrm{CAL}=$ clinical attachment loss

\section{DISCUSSION}

TNF- $\alpha$ and IL- $1 \alpha$ are two important cytokines in immune and inflammatory responses of the body. Bacterial lipopolysaccharides stimulate cellular receptors. After the ligation, intracellular messenger is activated and results in TNF and IL gene expression and some other cytokines. This process is the start of host response to pathogenic factors. Although destructive effects of these factors in inflammatory conditions have been reported in some studies, the beneficial and modifying effects of these factors in defense system of the host should not be underestimated. Comparison of clinical parameters such as PD, CAL, and BOP before and after scaling and root planning showed that all these items improved significantly. The results showed that salivary TNF- $\alpha$ level was lower in periodontitis group compared to control group. Non-surgical therapy (scaling and root planning) and omission of pathogenic factors resulted in increase in salivary TNF- $\alpha$ level and improvement in clinical indices such as pocket depth, attachment loss, and bleeding on probing. The result of study by Geng [38] and Rai [39] showed that TNF- $\alpha$ can be a biomarker for periodontal disease. However, in these two cross-sectional studies, higher level of TNF- $\alpha$ was reported in disease group compared to healthy group. In Rai study, patients with different types of periodontitis were studied. Here, we only included patients with chronic periodontitis to have more reliable results and this group was compared to gendermatched healthy group as control group. Similar to our result, in Ulker [40], Ng [41], and Aurer [42] studies, patients with periodontal disease were reported to have lower level of TNF- $\alpha$.

In Aurer study on different groups including chronic periodontitis patients, healthy group, and patients with tooth loss showed that in addition to TNF- $\alpha$, salivary levels of other inflammatory factors such as C3, CRP, and $\alpha-2 \mathrm{M}$ were lower in periodontitis group compared to other groups. The reduced levels of inflammatory proteins show that in such chronic inflammatory diseases, host immune response has been decreased [43, 44].

In addition to the mentioned studies, Shy [30] study reported increase in TNF- $\alpha$ level after non-surgical treatment and improvement in clinical indices. Despite common belief that periodontal pathogens cause progressive destruction of periodontal tissue via severe immune response induction, some in vitro studies showed that periodontal pathogens, compared to non-pathogenic factors, cause lower level of inflammatory cytokines induction [45 - 50]. In vitro study by Dickinson showed that Porphyromonas gingivalis which is usually seen in severe and chronic periodontitis has high potential to invade several epithelial layers but does not stimulate pro-inflammatory cytokines production. Streptococcus gordonii, which is dominantly existent on epithelial surface, causes continuous secretion of cytokines and controls over growth of other bacteria [45]. 
The results obtained here are in contradiction with studies by Sexton [51], Ebersole [52], Yousefimanesh [53], Gursoy [54], and Reis [55]. They reported TNF- $\alpha$ concentration was not affected by non-surgical therapy. In Sexton and Ebersole studies, being a smoker was not among exclusion criteria. But, cigarette smoking can affect TNF- $\alpha$ level in gingival sulcus and saliva.

The controversies seen between studies can be due to several factors including difference in type and severity of periodontal disease, age of the subjects, salivary sample or gingival sulcus sample, the temperature at which the samples were stores, storage time before laboratory assay, and centrifuge setting. In some studies (Ebersole and Sexton studies), Multiplex ELISA method was applied.

The current results showed that salivary IL- $1 \alpha$ level was statistically different between periodontitis and control group. In fact, salivary level of this factor was higher in control group. With scaling, salivary IL-1 $\alpha$ increased and approached to the control group, but this was not statistically different.

Shy study reported that salivary IL- $1 \alpha$ level increased in patients who responded to treatment [30]. In Front study, IL- $1 \alpha$ level showed a decrease by $51 \%$ after treatment. In this study, no control group was included [56]. The difference between the results of the mentioned study and our results can be due to difference in the time when the second sample was collected. In Front study, the second sample was obtained 10 to 14 weeks after therapy. The results of Reis study also showed that IL-1 $\alpha$ level increased significantly after treatment. However, Reis showed significant decrease in IL-1 $\alpha$ level obtained from gingival sulcus [55]. This difference in the kind of mouth fluid samples can be another factor justifying the difference observed between studies. Saliva is a combination of secretions from the salivary glands, the gingival sulcus fluid, and oral cavity cells. Studying pro-inflammatory factors concentration in salivary samples exhibit results which are in contrast to common belief about the role that the immune system and inflammatory markers in progression of periodontal tissue destruction.

\section{CONCLUSION}

According to the obtained findings, salivary TNF- $\alpha$ and IL-1 $\alpha$ levels were lower in patients with chronic periodontitis in comparison to control group. There was a significant association between these two factors and pocket depth and attachment loss. So, treatment of periodontal disease increased the salivary levels of these two markers.

\section{SUGGESTION}

Regarding the differences existing between designs of studies like the method of saliva collection or the gingival sulcus fluid, temperature and time of storage of samples until ELISA is performed, and centrifuge settings, we recommend a standard method for future studies. If standard and uniform method is done, comparisons between studies can be done. We suggest conducting studies with larger sample sizes and different follow-up times to achieve more general results.

\section{ETHICS APPROVAL AND CONSENT TO PARTICIPATE}

The study protocol was approved by the Ethics Committee of Kermanshah University of Medical sciences, Kermanshah, Iran (KUMS REC 1395.128). The study protocol was registered at the Iranian Registry of Clinical Trials (IRCT2016052825649N3).

\section{HUMAN AND ANIMAL RIGHTS}

The reported experiments in accordance with the ethical standards of the committee responsible for human experimentation (institutional and national), and with the Helsinki Declaration of 1975, as revised in 2008 (http://www.wma.net/en/20activities/10ethics/10helsinki/).

\section{CONSENT FOR PUBLICATION}

Not applicable.

\section{CONFLICT OF INTEREST}

The authors declare no conflict of interest, financial or otherwise. 


\section{ACKNOWLEDGEMENTS}

We take this opportunity to express gratitude to all of the patients for their participation in this research. The presented article is the result of a dissertation to get doctorate degree in dentistry at Kermanshah University of Medical Sciences, Kermanshah, Iran.

\section{REFERENCES}

[1] Cafiero C, Matarasso M, Marenzi G, Iorio Siciliano V, Bellia L, Sammartino G. Periodontal care as a fundamental step for an active and healthy ageing. Scientific World J 2013; 1-7.

[http://dx.doi.org/10.1155/2013/127905]

[2] Ji S, Choi YS, Choi Y. Bacterial invasion and persistence: Critical events in the pathogenesis of periodontitis. J Periodontal Res 2015; 50(5): $570-85$. [http://dx.doi.org/10.1111/jre.12248] [PMID: 25487426]

[3] Corbet EF, Zee KY, Lo EC. Periodontal diseases in Asia and Oceania. Periodontol 2000 2002; 29(1): $122-52$. [http://dx.doi.org/10.1034/j.1600-0757.2002.290107.x] [PMID: 12102706]

[4] Lang NP, Suvan JE, Tonetti MS. Risk factor assessment tools for the prevention of periodontitis progression. A systematic review. J Clin Periodontol 2015; 42(S16)(Suppl. 16): S59-70. [http://dx.doi.org/10.1111/jcpe.12350] [PMID: 25496279]

[5] Lawrence HP, Thomson WM, Broadbent JM, Poulton R. Oral health-related quality of life in a birth cohort of 32-years olds. Community Dent Oral Epidemiol 2008; 36(4): 305-16.

[http://dx.doi.org/10.1111/j.1600-0528.2007.00395.x] [PMID: 18650957]

[6] Lopes MW, Gusmão ES, de Vasconcelos Alves R, Cimões R. The impact of chronic periodontitis on quality of life in Brazilian subjects. Acta Stomatol Croat 2009; 43(2): 89-98.

[7] Genco RJ, Van Dyke TE. Prevention: Reducing the risk of CVD in patients with periodontitis. Nat Rev Cardiol 2010; 7(9): 479-80. [http://dx.doi.org/10.1038/nrcardio.2010.120] [PMID: 20725103]

[8] Kebschull M, Demmer RT, Papapanou PN. Gum bug, leave my heart alone!: Epidemiologic and mechanistic evidence linking periodontal infections and atherosclerosis. J Dent Res 2010; 89(9): 879-902. [http://dx.doi.org/10.1177/0022034510375281] [PMID: 20639510]

[9] Lalla E, Papapanou PN. Diabetes mellitus and periodontitis: A tale of two common interrelated diseases. Nat Rev Endocrinol 2011; 7(12): 738-48. [http://dx.doi.org/10.1038/nrendo.2011.106] [PMID: 21709707]

[10] Lundberg K, Wegner N, Yucel-Lindberg T, Venables PJ. Periodontitis in RA-the citrullinated enolase connection. Nat Rev Rheumatol 2010; 6(12): 727-30.

[http://dx.doi.org/10.1038/nrrheum.2010.139] [PMID: 20820197]

[11] Madianos PN, Bobetsis YA, Offenbacher S. Adverse pregnancy outcomes (APOs) and periodontal disease: Pathogenic mechanisms. J Clin Periodontol 2013; 40(4)(Suppl. 14): S170-80.

[PMID: 23627327]

[12] Genco RJ, Borgnakke WS. Risk factors for periodontal disease. Periodontol 2000 2013; 62(1): 59-94. [http://dx.doi.org/10.1111/j.1600-0757.2012.00457.x] [PMID: 23574464]

[13] Hajishengallis G, Lamont RJ. Beyond the red complex and into more complexity: The polymicrobial synergy and dysbiosis (PSD) model of periodontal disease etiology. Mol Oral Microbiol 2012; 27(6): 409-19. [http://dx.doi.org/10.1111/j.2041-1014.2012.00663.x] [PMID: 23134607]

[14] Ji S, Choi Y. Innate immune response to oral bacteria and the immune evasive characteristics of periodontal pathogens. J Periodontal Implant Sci 2013; 43(1): 3-11. [http://dx.doi.org/10.5051/jpis.2013.43.1.3] [PMID: 23507986]

[15] Hajishengallis G. Immunomicrobial pathogenesis of periodontitis: Keystones, pathobionts, and host response. Trends Immunol 2014; 35(1): $3-11$. [http://dx.doi.org/10.1016/j.it.2013.09.001] [PMID: 24269668]

[16] Pihlstrom BL, Michalowicz BS, Johnson NW. Periodontal diseases. Lancet 2005; 366(9499): 1809-20. [http://dx.doi.org/10.1016/S0140-6736(05)67728-8] [PMID: 16298220]

[17] Preshaw PM, Taylor JJ. How has research into cytokine interactions and their role in driving immune responses impacted our understanding of periodontitis. J Clin Periodontol 2011; 38(s11)(Suppl. 11): 60-84. [http://dx.doi.org/10.1111/j.1600-051X.2010.01671.x] [PMID: 21323705]

[18] Abbas AK, Lichtman AH, Pillai S. Cellular and molecular immunology. $8^{\text {th }}$ ed. Elsevier Health Sci 2014 ; p. 544.

[19] Arend WP, Palmer G, Gabay C. IL-1, IL-18, and IL-33 families of cytokines. Immunol Rev 2008; 223(1): 20-38. [http://dx.doi.org/10.1111/j.1600-065X.2008.00624.x] [PMID: 18613828] 
[20] Barksby HE, Lea SR, Preshaw PM, Taylor JJ. The expanding family of interleukin-1 cytokines and their role in destructive inflammatory disorders. Clin Exp Immunol 2007; 149(2): 217-25. [http://dx.doi.org/10.1111/j.1365-2249.2007.03441.x] [PMID: 17590166]

[21] Sims JE, Smith DE. The IL-1 family: Regulators of immunity. Nat Rev Immunol 2010; 10(2): 89-102. [http://dx.doi.org/10.1038/nri2691] [PMID: 20081871]

[22] Petropoulos G, McKay IJ, Hughes FJ. The association between neutrophil numbers and interleukin-1 $\alpha$ concentrations in gingival crevicular fluid of smokers and non-smokers with periodontal disease. J Clin Periodontol 2004; 31(5): 390-5. [http://dx.doi.org/10.1111/j.1600-051x.2004.00489.x] [PMID: 15086622]

[23] Bartold PM, Marshall RI, Haynes DR. Periodontitis and rheumatoid arthritis: a review. J Periodontol 2005; 76(11)(Suppl.): 2066-74. [http://dx.doi.org/10.1902/jop.2005.76.11-S.2066] [PMID: 16277578]

[24] Haynes DR. Bone lysis and inflammation. Inflamm Res 2004; 53(11): 596-600. [http://dx.doi.org/10.1007/s00011-004-1303-z] [PMID: 15693607]

[25] Azuma Y, Kaji K, Katogi R, Takeshita S, Kudo A. Tumor necrosis factor- $\alpha$ induces differentiation of and bone resorption by osteoclasts. J Biol Chem 2000; 275(7): 4858-64. [http://dx.doi.org/10.1074/jbc.275.7.4858] [PMID: 10671521]

[26] Bertolini DR, Nedwin GE, Bringman TS, Smith DD, Mundy GR. Stimulation of bone resorption and inhibition of bone formation in vitro by human tumour necrosis factors. Nature 1986; 319(6053): 516-8. [http://dx.doi.org/10.1038/319516a0] [PMID: 3511389]

[27] Katagiri T, Takahashi N. Regulatory mechanisms of osteoblast and osteoclast differentiation. Oral Dis 2002; 8(3): 147-59. [http://dx.doi.org/10.1034/j.1601-0825.2002.01829.x] [PMID: 12108759]

[28] Kobayashi K, Takahashi N, Jimi E, et al. Tumor necrosis factor $\alpha$ stimulates osteoclast differentiation by a mechanism independent of the ODF/RANKL-RANK interaction. J Exp Med 2000; 191(2): 275-86. [http://dx.doi.org/10.1084/jem.191.2.275] [PMID: 10637272]

[29] Zhang G-Y, Yu Z-H, Zhang X-H, Du J-D, Yang Q, He F-D. Influence of TGF- $\beta$ _ 1 on proliferation and differentiation of HPDLFs in vitro. Shandong Med J 2008; 48(21)

[30] Shyu K-G, Choy C-S, Wang DC-L, et al. Change of scaling-induced proinflammatory cytokine on the clinical efficacy of periodontitis treatment 2015. [http://dx.doi.org/10.1155/2015/289647]

[31] Takeuchi R, Ryo A, Komitsu N, et al. Low-intensity pulsed ultrasound activates the phosphatidylinositol 3 kinase/Akt pathway and stimulates the growth of chondrocytes in three-dimensional cultures: a basic science study. Arthritis Res Ther 2008; 10(4): R77. [http://dx.doi.org/10.1186/ar2451] [PMID: 18616830]

[32] Toyama Y, Sasaki K, Tachibana K, et al. Ultrasound stimulation restores impaired neovascularization-related capacities of human circulating angiogenic cells. Cardiovasc Res 2012; 95(4): 448-59. [http://dx.doi.org/10.1093/cvr/cvs173] [PMID: 22641844]

[33] Abdolsamadi HR, Rezaei F, Goodarzi MT, et al. Comparison of salivary nitric oxide and epidermal growth factor level between diabetic patients and healthy individuals. Int J Diabetes Dev Ctries 2015; 35(3): 477-82. [http://dx.doi.org/10.1007/s13410-014-0207-x]

[34] Rahmani M, Ghorchi V, Rezaei F, Vaisi-Raygani A. Evaluation of Total Antioxidant Capacity of Saliva in High School Students. Glob J Health Sci 2015; 8(4): 89-94. [http://dx.doi.org/10.5539/gjhs.v8n4p89] [PMID: 26573023]

[35] Armitage GC. Development of a classification system for periodontal diseases and conditions. Ann Periodontol 1999; 4(1): 1-6. [http://dx.doi.org/10.1902/annals.1999.4.1.1] [PMID: 10863370]

[36] Navazesh M. Methods for collecting saliva. Ann N Y Acad Sci 1993; 694(1): 72-7. [http://dx.doi.org/10.1111/j.1749-6632.1993.tb18343.x] [PMID: 8215087]

[37] Stahl SS, Weiner JM, Benjamin S, Yamada L. Soft tissue healing following curettage and root planing. J Periodontol 1971; 42 (11): 678-84. [http://dx.doi.org/10.1902/jop.1971.42.11.678] [PMID: 5288562]

[38] Geng W-y, Ying-Hui T, Sheng-Gen S. Expression of IL-6 and TNF- $\alpha$ activities in saliva of chronic periodontitic patients. Yati Yasui Yazhoubingxue Zazhi 2009; 5: 11.

[39] Rai B. Salivary levels of tumor necrosis factor-alpha in periodontitis. Adv Med Dent Sci 2008; pp. 40-2.

[40] Ülker AE, Tulunoglu O, Özmeric N, Can M, Demirtas S. The evaluation of cystatin C, IL-1 $\beta$, and TNF- $\alpha$ levels in total saliva and gingival crevicular fluid from 11- to 16-year-old children. J Periodontol 2008; 79(5): 854-60. [http://dx.doi.org/10.1902/jop.2008.070422] [PMID: 18454664]

[41] Ng PY, Donley M, Hausmann E, Hutson AD, Rossomando EF, Scannapieco FA. Candidate salivary biomarkers associated with alveolar bone loss: cross-sectional and in vitro studies. FEMS Immunol Med Microbiol 2007; 49(2): 252-60. [http://dx.doi.org/10.1111/j.1574-695X.2006.00187.x] [PMID: 17328758] 
[42] Aurer A, Jorgić-Srdjak K, Plančak D, Stavljenić-Rukavina A, Aurer-Koželj J. Proinflammatory factors in saliva as possible markers for periodontal disease. Coll Antropol 2005; 29(2): 435-9. [PMID: 16417140]

[43] Brock GR, Butterworth CJ, Matthews JB, Chapple IL. Local and systemic total antioxidant capacity in periodontitis and health. J Clin Periodontol 2004; 31(7): 515-21. [http://dx.doi.org/10.1111/j.1600-051X.2004.00509.x] [PMID: 15191586]

[44] Sculley DV, Langley-Evans SC. Salivary antioxidants and periodontal disease status. Proc Nutr Soc 2002; 61(1): 137-43. [http://dx.doi.org/10.1079/PNS2001141] [PMID: 12002788]

[45] Dickinson BC, Moffatt CE, Hagerty D, et al. Interaction of oral bacteria with gingival epithelial cell multilayers. Mol Oral Microbiol 2011; 26(3): 210-20.

[http://dx.doi.org/10.1111/j.2041-1014.2011.00609.x] [PMID: 21545698]

[46] Ji S, Hyun J, Park E, Lee BL, Kim KK, Choi Y. Susceptibility of various oral bacteria to antimicrobial peptides and to phagocytosis by neutrophils. J Periodontal Res 2007; 42(5): 410-9.

[http://dx.doi.org/10.1111/j.1600-0765.2006.00962.x] [PMID: 17760818]

[47] Kirschbaum M, Schultze-Mosgau S, Pfister W, Eick S. Mixture of periodontopathogenic bacteria influences interaction with KB cells. Anaerobe 2010; 16(4): 461-8. [http://dx.doi.org/10.1016/j.anaerobe.2010.03.009] [PMID: 20380884]

[48] Peyyala R, Kirakodu SS, Novak KF, Ebersole JL. Oral microbial biofilm stimulation of epithelial cell responses. Cytokine 2012 ; 58(1): 65-72. [http://dx.doi.org/10.1016/j.cyto.2011.12.016] [PMID: 22266273]

[49] Shin J, Ji S, Choi Y. Ability of oral bacteria to induce tissue-destructive molecules from human neutrophils. Oral Dis 2008; 14(4): 327-34. [http://dx.doi.org/10.1111/j.1601-0825.2007.01382.x] [PMID: 18449962]

[50] Shin JE, Choi Y. Treponema denticola suppresses expression of human $\beta$-defensin-2 in gingival epithelial cells through inhibition of TNFalpha production and TLR2 activation. Mol Cells 2010; 29(4): 407-12. [http://dx.doi.org/10.1007/s10059-010-0048-5] [PMID: 20213311]

[51] Sexton WM, Lin Y, Kryscio RJ, Dawson DR III, Ebersole JL, Miller CS. Salivary biomarkers of periodontal disease in response to treatment. J Clin Periodontol 2011; 38(5): 434-41.

[http://dx.doi.org/10.1111/j.1600-051X.2011.01706.x] [PMID: 21480939]

[52] Ebersole JL, Schuster JL, Stevens J, et al. Patterns of salivary analytes provide diagnostic capacity for distinguishing chronic adult periodontitis from health. J Clin Immunol 2013; 33(1): 271-9. [http://dx.doi.org/10.1007/s10875-012-9771-3] [PMID: 22926406]

[53] Yousefimanesh H, Maryam R, Mahmoud J, Mehri GB, Mohsen T. Evaluation of salivary tumor necrosis factor-alpha in patients with the chronic periodontitis: A case-control study. J Indian Soc Periodontol 2013; 17(6): 737-40. [http://dx.doi.org/10.4103/0972-124X.124490] [PMID: 24554882]

[54] Gursoy UK, Könönen E, Uitto VJ, et al. Salivary interleukin-1 $\beta$ concentration and the presence of multiple pathogens in periodontitis. J Clin Periodontol 2009; 36(11): 922-7.

[http://dx.doi.org/10.1111/j.1600-051X.2009.01480.x] [PMID: 19799718]

[55] Reis C, DA Costa AV, Guimarães JT, et al. Clinical improvement following therapy for periodontitis: Association with a decrease in IL-1 and IL-6. Exp Ther Med 2014; 8(1): 323-7. [PMID: 24944641]

[56] Front E, Laster Z, Unis R, Gavish M, Nagler RM. Salivary biomarker analysis complementing regular clinical examination. Biomarkers Med 2013; 7(5): 701-8.

[http://dx.doi.org/10.2217/bmm.13.76] [PMID: 24044562]

(C) 2017 Eivazi et al.

This is an open access article distributed under the terms of the Creative Commons Attribution 4.0 International Public License (CC-BY 4.0), a copy of which is available at: https://creativecommons.org/licenses/by/4.0/legalcode. This license permits unrestricted use, distribution, and reproduction in any medium, provided the original author and source are credited. 